\title{
Estabilidade Macroeconômica no Brasil: do Imposto Inflacionário ao Populismo
}

\author{
Marcos Santos Meneghini
}

\section{Introdução}

O ano de 2016 mostrou-se bastante conturbado no Brasil social, política e economicamente. Assistimos ao segundo impeachment de um Presidente da República em menos de trinta anos de regime democrático pleno, a greves de diversas categorias de trabalhadores, à intensificação da polarização política e à maior recessão já enfrentada pelo país ${ }^{1}$. Existe um sentimento de insatisfação social generalizado refletido também nos índices de aprovação de diversos chefes dos poderes executivos federal, estadual e municipal e exacerbado através de manifestações contrárias a reformas apresentadas para a equalização do colapso fiscal nos diferentes níveis da federação.

Após a definição do abrangente estado de bem estar social brasileiro em 1988, da onerosa estabilização macroeconômica iniciada em 1994 e da expansão da demanda financiada por commodities do início do século XXI, o país aparentemente caminhava para uma direção de crescimento sustentável com distribuição de renda. Como o Brasil alcançou o atual ponto de sua história econômica? Havia como evitar esse revés no processo de desenvolvimento em curso, conforme nos mostram os indicadores econômico-sociais recentes?

Joseph A. Schumpeter, um dos maiores economistas do século XX, escreve na introdução de sua obra "História da Análise Econômica" que o título significava a história do esforço intelectual feito pelo homem a fim de conhecer os fenômenos econômicos, ou, de forma similar, a história dos aspectos analíticos e científicos do pensamento econômico (Schumpeter, 1964). Sobre os benefícios de se estudar a história de qualquer ciência destacava que pode-se aprender sobre os métodos que funcionam - como e por quê - em dadas circunstâncias. O objeto de estudo da ciência econômica seria, por si só, um processo histórico único. Não se poderia, desta forma, tentar entender os fenômenos econômicos de qualquer época - incluindo o presente - sem o domínio dos fatos históricos. Schumpeter acreditava que a maioria dos erros cometidos na análise econômica era proveniente da falta de experiência histórica, e não da falta instrumentos analíticos.

Entre os obstáculos que o autor austro-americano vislumbrava ter que superar para sua obra atingir o objetivo - analisar a evolução das técnicas que permitem

\footnotetext{
${ }^{1}$ A taxa de crescimento do Produto Interno Bruto em 2016 foi de -3,6\%; em 2015, o PIB havia recuado 3,8\% (Banco Central 2017).
}

RASILIANA-Journal for Brazilian Studies. Vol. 6, n.2 (October, 2018). ISSN 2245-4373. 
descrever e explicar os aspectos econômicos da realidade - o principal seria a ideologia, uma vez que o trabalho analítico "begins with material provided by our vision of things, and this vision is ideological almost by definition" (Schumpeter 1964). O autor também considerava importante fazer um esboço do "espírito do tempo" das épocas históricas abrangidas por seu estudo e, para isso, utilizou-se da descrição prévia de aspectos políticos às suas exposições sobre a análise econômica. Embora inevitável a abordagem de algumas características do espectro político, o objetivo deste artigo consiste em avaliar a evolução dos arranjos institucionais brasileiros - aqui entendidos como o conjunto de leis e regras fiscais e monetárias que balizam a conduta dos agentes - no que concerne à garantia da estabilidade macroeconômica, entre 1945 e 2015, caracterizando em especial o período mais recente (2006-2015) dentro do arcabouço teórico definido por Dornbusch e Edwards (1991).

Além dessas considerações iniciais, o artigo apresenta mais quatro seções distribuídas da seguinte forma: o imposto inflacionário (1945-1994); a estabilização macroeconômica (1994-2000) e o primeiro Governo Lula; o populismo macroeconômico no período 2006-2015; conclusões.

\section{O imposto inflacionário (1945-1994)}

\subsection{Inflação e instabilidade}

O que acontece quando o Governo financia sistematicamente o seu déficit via expansão da base monetária? A resposta imediata é que o déficit real do setor público terá que ser coberto pelo aumento real da base monetária mais a arrecadação do imposto inflacionário. Se o primeiro não for suficiente para cobrir todo o déficit público, os preços terão que subir continuadamente para que as contas reais do Governo fechem via arrecadação do imposto inflacionário (Simonsen e Cysne 2009).

A alta inflação média do Brasil no pós II Guerra e suas flutuações ao longo do tempo, conforme relatado na Tabela 1 , refletiram mudanças drásticas na distribuição do poder político em uma sociedade cuja elevada concentração de renda e riqueza tem origem na forma de ocupação colonial².

\footnotetext{
${ }^{2}$ Sobre as origens coloniais da desigualdade brasileira ver Prado Junior (1942). 
Tabela 1 - Padrões monetários brasileiros, 1942-2013

\begin{tabular}{llllll}
$\begin{array}{l}\text { Padrão } \\
\text { monetário }\end{array}$ & Início & $\begin{array}{l}\text { Duração } \\
\text { (em meses) }\end{array}$ & $\begin{array}{l}\text { Inflação } \\
\text { acumulada } \\
(\mathbf{\%})\end{array}$ & $\begin{array}{l}\text { Inflação } \\
\text { média } \\
\text { mensal (\%) }\end{array}$ & $\begin{array}{l}\text { Inflação } \\
\text { média } \\
\text { anual (\%) }\end{array}$ \\
\hline Cruzeiro & nov/42 & 292 & 31.191 & 2,0 & 27 \\
Cruzeiro Novo & fev/67 & 40 & 90 & 1,6 & 21 \\
Cruzeiro & jun/70 & 190 & 206.288 & 4,1 & 62 \\
Cruzado & mar/86 & 35 & 5.699 & 12,3 & 302 \\
Cruzado Novo & jan/89 & 15 & 5.937 & 31,4 & 2.559 \\
Cruzeiro & mar/90 & 41 & 118.590 & 18,8 & 694 \\
Cruzeiro Real & ago/93 & 11 & 2.396 & 34,0 & 3.244 \\
Real * & fev/94 & 238 & 345 & 0,6 & 7,4 \\
\hline
\end{tabular}

Fonte: Franco (2017)

\section{Nota: * Inflação medida pelo IPCA até dezembro de 2013.}

De acordo com Calomiris e Haber (2014), as forças resultantes dessa desigualdade impuseram aos governos brasileiros três opções pouco atraentes para se financiar: manter uma pequena base tributária e, consequentemente, uma estrutura burocrática fraca; taxar os pobres através da inflação; ou taxar os ricos. Enquanto o sistema político do Brasil foi descentralizado e dominado por oligarquias locais - entre 1822 e 1889, na época Imperial - uma pequena elite latifundiária obteve sucesso em manter o governo central pequeno e fraco.

Após a proclamação da República o sistema político evoluiu disponibilizando ao poder público ferramentas fortes o suficiente para a consolidação de alianças com os principais grupos de interesse organizados (agro-exportadores, industriais, funcionários públicos, financistas); nessa configuração, que dominou a maior parte da história brasileira (entre 1889 e 1988), a inflação foi tipicamente o caminho de menor resistência para financiar o governo e resolver o conflito distributivo uma vez que seus custos são difusos e recaem, principalmente, sobre a massa excluída dos processos decisórios.

Já em uma democracia plena, como a estabelecida pela Constituição de 1988, a parcela da população que arca com a maior parte das consequências inflacionárias em geral os mais pobres - tem amplos direitos individuais garantidos, inclusive ao voto e, consequentemente, esta forma de arrecadação torna-se menos viável. Ou seja, a solução para as restrições orçamentárias do governo brasileiro (e de grupos de interesse organizados) após o final da II Guerra perpassa, primeiramente, pela cobrança de um imposto inflacionário e, posteriormente, pela emissão de dívida, como será discutido doravante. 
Talvez o maior exemplo de correlação entre descontrole inflacionário e instabilidade político-econômica seja o período que abrange o Governo Juscelino Kubitschek até o golpe militar em março de 1964. De acordo com Pastore (2015) a estratégia de industrialização por substituição de importações do Plano de Metas (1956-1960) caracterizou-se pela total irresponsabilidade fiscal, falhando em especificar minimamente os mecanismos de fianciamento para um conjunto ambicioso de investimentos. O índice geral de preços (IGP) passou de 12,1\% em 1955 para 79,9\% em 1963. O controle inflacionário só viria após a implementação em 1964, já no regime militar, do PAEG - Programa de Ação Econômica do Governo - que, ao combinar uma política de queda nos salários reais com um corte no défict público de $4 \%$ para $1 \%$ do PIB, permitiu o ajuste no balaço de pagamentos e IGP de 25\% em 1967.

Na Figura 1 a seguir demonstra-se a arrecadação e distribuição do imposto inflacionário ${ }^{3}$ entre 1947 e 1987 como porcentagem do PIB. Percebe-se, claramente, que a crise do início dos anos 1960 representou enorme custo social via cobrança do imposto; o recrudescimento observado em 1987 é devido ao fracasso do Plano Cruzado, lançado em 1986.

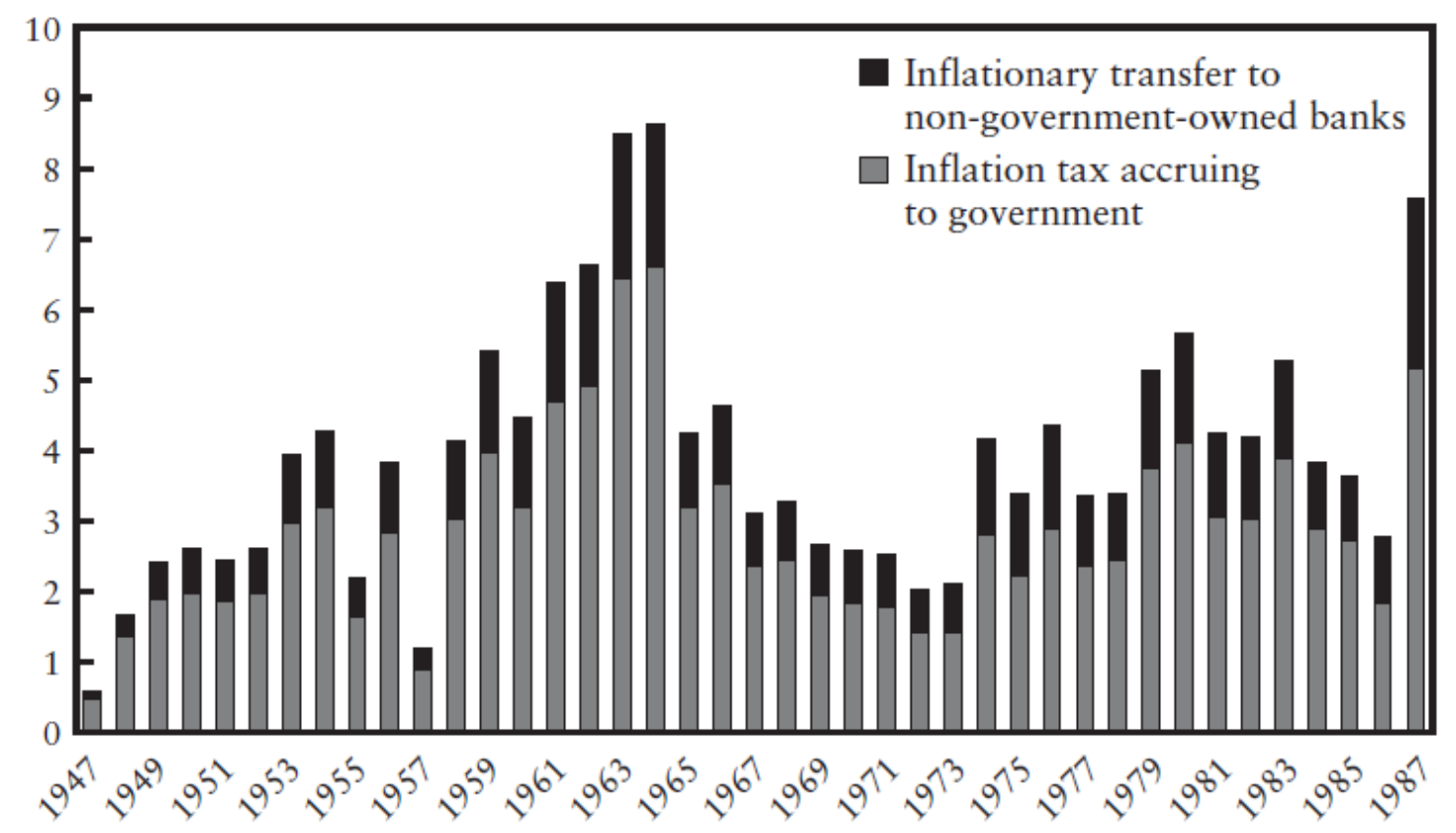

Figura 1 - O imposto inflacionário - Fonte: Calomiris e Haber (2014)

\footnotetext{
${ }^{3} \mathrm{O}$ conceito de imposto inflacionário refere-se à perda compulsória do poder de compra dos agentes econômicos que detém numerário não corrigido por juros (dinheiro em espécie ou depósitos à vista), via emissão de moeda pelo Banco Central.
} 


\subsection{A governança da moeda}

Na esteira da Conferência de Bretton Woods, que exigia maior disciplina dos sistemas cambiais mundiais no pós-guerra, foi criada, em 2.2.1945, a SUMOC Superintendência da Moeda e do Crédito, com base na proposta de Octávio Gouvêa de Bulhões (Decreto-Lei $\left.n^{\circ} 7.293 / 1945\right)$. Embora as discussões sobre a importância de um Banco Central remontassem aos anos 1920, o Banco do Brasil permaneceria investido de muitas funções típicas de uma autoridade monetária até 1964. Havia grande resistência política frente a criação de um Banco Central independente por um amplo espectro de agentes econômicos cujos interesses reforçavam aqueles dos funcionários do Banco do Brasil, "desejosos de preservar o status quo" (Senna 2014, p.7). Esta mistura entre banco comercial e autoridade monetária impossibilitava o controle efetivo sobre a emissão de moeda, com consequentes efeitos inflacionários.

Em 31.12.1964, no primeiro ano da ditadura militar, foi sancionada a Lei no 4.595 que, ao regulamentar o Sistema Financeiro Nacional, estabeleceu a criação do Banco Central do Brasil. Mesmo assim, conforme destacado por Franco (2015), a independência da instituição "fora revogada sem piedade pelos golpistas e, pior, o sistema foi reorganizado de forma a que o $\mathrm{BC}$ se tornasse a casa de máquinas de uma extensa e ambiciosa agenda de desenvolvimento centralizada no $\mathrm{CMN}^{4 \prime \prime}$. Àquela época a operacionalização da política monetária era realizada através do controle da base monetária, e não da taxa básica de juros, e o instrumento utilizado pelo CMN para determinar o comportamento da oferta monetária consistia no orçamento monetário, por meio do qual eram fixados tetos para as operações ativas dos bancos e cuja soma determinava a expansão da base monetária.

Para compensar o Banco do Brasil pela perda de parte de suas atribuições com o advento do Conselho foi criada, em 1965, a conta movimento, que o mantinha na condição de agente financeiro do Banco Central. Com o decorrer do tempo essa conta passou a ser utilizada como suprimento automático de recursos ao $\mathrm{BB}$, de forma paralela aos ritos orçamentários do Congresso Nacional e com claros efeitos inflacionários. A Tabela 2, extraída de Jaloretto (2006), apresenta os saldos da Conta Movimento entre 1965 e 1982 e, nas palavras do autor, "dando uma dimensão aproximada do financiamento ao Banco do Brasil e, por extensão, ao Tesouro pelo Banco Central", ou seja, a parte da receita de senhoriagem ${ }^{5}$ não apropriada pelo Banco

\footnotetext{
${ }^{4}$ O Conselho Monetário Nacional (CMN) foi criado para ser o órgão de cúpula do Sistema Financeiro Nacional, normativo e decisório, composto inicialmente pelos ministros da Fazenda (Presidente), do Planejamento, da Agricultura, da Indústria e Comércio, pelos presidentes do Banco do Brasil e do BNDE, além de diretores do Banco Central e representantes do setor privado. A estrutura do CMN mudou ao longo dos anos, chegando a atingir a incrível marca de 21 membros às vésperas do Plano Real. Atualmente, o CMN é composto apenas pelo presidente do BC e dos ministros da Fazenda e do Planejamento (Lei no 9.069/1995).

${ }^{5}$ Senhoriagem pode ser definida como a diferença entre o valor de face de uma moeda e seu custo de fabricação. Em tese, trata-se dos bens e serviços que um Banco Central poderia adquirir pelo fato de ser o monopolista na emissão de papel moeda.
} 
Central subsidiou diretamente o Tesouro Nacional e demais operações de fomento do governo federal.

Tabela 2 - Créditos do Banco Central no Banco do Brasil - \% PIB

\begin{tabular}{lllll}
\hline Ano & Conta Movimento & Suprimentos especiais ao BB & Total & Base monetária \\
\hline 1965 & 0,72 & 2,32 & 3,04 & 7,41 \\
1966 & 0,78 & 1,68 & 2,46 & 6,15 \\
1967 & 1,80 & 1,33 & 3,13 & 6,40 \\
1968 & 2,46 & 0,98 & 3,43 & 6,29 \\
1969 & 3,64 & 0,75 & 4,39 & 6,00 \\
1970 & - & - & - & 5,48 \\
1971 & 3,83 & 0,50 & 4,33 & 5,48 \\
1972 & 3,47 & 0,38 & 3,85 & 4,81 \\
1973 & 2,61 & 0,26 & 2,86 & 4,82 \\
1974 & 1,82 & 0,16 & 1,98 & 3,90 \\
1975 & 4,10 & 0,12 & 4,21 & 3,81 \\
1976 & 3,48 & 0,07 & 3,55 & 3,73 \\
1977 & 4,34 & 0,05 & 4,39 & 4,32 \\
1978 & 4,79 & 0,03 & 4,82 & 4,45 \\
1979 & 4,69 & 0,02 & 4,71 & 4,19 \\
1980 & 3,91 & 0,01 & 3,92 & 3,41 \\
1981 & 3,72 & 0,00 & 3,72 & 3,39 \\
1982 & 3,19 & 0,00 & 3,19 & 3,27 \\
\hline Média & 3,14 & $\mathbf{0 , 5 1}$ & 3,65 & $\mathbf{4 , 8 5}$ \\
\hline
\end{tabular}

Fonte: Jaloretto (2006).

Nota: * Suprimentos de recursos específicos (art. 19 da Lei 4.595/64)

Até a Constituição de 1988 entrar em vigência o CMN - cercado de conflitos de interesse devido à sua heterogênea composição - detinha poderes bastante amplos, situação que só foi alterada pelo resgate de prerrogativas do Poder Legislativo com a inclusão, no Orçamento da União, das operações oficiais de crédito e com o fim do orçamento monetário. Todavia, este arranjo institucional precário resistiu por 50 anos e, entre o fim da conta movimento, em 1986, e a estabilização monetária em 1994, passaram-se ainda cinco choques heterodoxos que culminaram num processo hiperinflacionário, com a taxa anual de variação dos preços atingindo impressionantes $2.477 \%$ em 1993. As consequências para a sociedade brasileira deste longo processo até o controle sobre a moeda, em termos de concentração de renda e riqueza, desempenharam papel fundamental no atraso do desenvolvimento econômico nacional. Conforme destacado pelo Banco Central do Brasil (2013): 
"A evidência internacional, no que é ratificada pela experiência brasileira, indica que taxas de inflação elevadas levam ao aumento dos prêmios de risco, tanto para o financiamento privado quanto para o público; ao encurtamento dos horizontes de planejamento, tanto das famílias quanto das empresas. Consequentemente, taxas de inflação elevadas reduzem os investimentos e o potencial de crescimento da economia, além de terem efeitos regressivos sobre a distribuição de renda. De outra forma, taxas de inflação elevadas não trazem qualquer resultado duradouro em termos de crescimento da economia e do emprego, mas, em contrapartida, trazem prejuízos permanentes para essas variáveis no médio e no longo prazo." (Banco Central 2013, item $\left.\mathrm{n}^{\circ} 22\right)$

\section{A estabilização macroeconômica e o primeiro Governo Lula}

\subsection{O fim do imposto inflacionário e o novo arranjo institucional (1994-2000)}

De acordo com Gremaud et al. (2002), o Plano Real se dividiu em três fases: (i) ajuste fiscal; (ii) indexação da economia através da Unidade Real de Valor (URV); e (iii) reforma monetária. O ajuste fiscal iniciado em meados de 1993 se baseava no corte de despesas, no aumento de impostos e na redução das transferências do governo federal. A implementação da URV foi iniciada em 1994 mantendo-se inicialmente a paridade de um para um com o dólar, além de metas para a expansão monetária (âncora monetária); posteriormente, foi estabelecida a âncora cambial com a flutuação da moeda norte americana dentro de bandas pré-estabelecidas pelo Banco Central ${ }^{6}$. Por fim, em 1.7.1994 houve a troca da moeda com a conversão de Cruzeiros para Reais, na proporção de $\mathrm{CR} \$ 2.750,00$ para $\mathrm{R} \$ 1,00$.

Para atender o aumento de gastos decorrente da Constituição de 1988 e à demanda oriunda do fim do imposto inflacionário, e ao mesmo tempo manter o câmbio dentro das bandas estabelecidas - a âncora nominal do Real - houve a elevação da dívida pública de forma simultânea à elevação da taxa de juros. Assim, fazia-se necessário desatrelar o Real do dólar de forma que a taxa de juros não fosse mais determinada a fim de manter a taxa de câmbio, mesmo incorrendo-se o risco da volta da inflação com o abandono da âncora cambial. Sob a influência decisiva da crise asiática de 1998 e do consequente ataque especulativo ao Real foi estabelecido um novo

\footnotetext{
${ }^{6}$ Em Outubro de 1994 a faixa de flutuação ficou determinada entre $\mathrm{R} \$ 0,84$ e $\mathrm{R} \$ 0,86$ por dólar.
} 
arranjo institucional entre as políticas fiscal e monetária, que ficou conhecido como o "tripé macroeconômico".

A primeira perna do tripé consiste na taxa de câmbio flutuante (a moeda passou a flutuar em 15.1.1999) e, dessa forma, "o câmbio cuidaria das contas externas e o juro da inflação, justamente o contrário do que vigorava anteriormente" (Pastore 2015, p. 158). A segunda perna do tripé consiste na disciplina fiscal capaz de reduzir o custo com os serviços da dívida pública, basicamente através de superávits primários. A Lei Complementar $n^{\circ} 101$, de 4 de maio de 2000, ou Lei de Responsabilidade Fiscal (LRF), significou um marco na gestão das finanças públicas brasileiras. Segundo Lima (2002), a LRF representou um novo paradigma na cultura fiscal brasileira, fixando critérios para a criação de despesas permanentes, a concessão de incentivos fiscais e inserindo o orçamento público no debate mais amplo da política macroeconômica do país. Por fim, o regime de metas para a inflação fornece a nova âncora nominal para o arranjo a própria inflação - através da coordenação das expectativas inflacionárias ${ }^{7}$, configurando a estrutura do tripé.

\subsection{O primeiro Governo Lula}

Após a crise de confiança nos mercados gerada pelo avanço eleitoral de Lula em 2002 e a alteração do discurso do Partido dos Trabalhadores (PT) registrada na "Carta ao Povo Brasileiro", o governo eleito em 2003 avançou em agendas macroeconômicas ortodoxas como, por exemplo, o estabelecimento de metas de inflação de 8,5\% e 5,5\% para 2003 e 2004 reforçando a política anti-inflacionária, a elevação da taxa Selic de $25 \%$ para $26,5 \%$, o aperto da meta de superávit primário de $3,75 \%$ para $4,25 \%$ do PIB e inserção na Lei de Diretrizes Orçamentárias (LDO) da manutenção da mesma meta para o período 2004-2006 ${ }^{8}$. De fato, o novo arranjo das instituições macroeconômicas brasileiras delineado pelo o regime de metas para inflação, pelo cambio flutuante e pela LRF teve continuidade nos primeiros anos do governo Lula, com a gradual recuperação da poupança pública e da confiança dos mercados e culminando na obtenção de grau de investimento soberano em maio de 2008.

Contudo, ainda no segundo semestre de 2005 a rejeição da cúpula do PT ao projeto de ajuste de longo prazo das contas públicas (déficit nominal zero em dez anos) proposto pelos Ministérios da Fazenda e Planejamento sinalizou que a postura do governo estava mudando. De acordo com Werneck (2014, p. 366), a proposta acabou

\footnotetext{
7 Ver "Dez anos de metas para inflação - 1999-2009", Banco Central do Brasil (2011).

${ }^{8}$ Para maior detalhamento do período ver Giambiagi e Pinheiro (2012).
} 
inviabilizada pela então nova chefe da Casa Civil, Dilma Rousseff ${ }^{9}$, e por Guido Mantega, então presidente do BNDES, com assentimento tácito da Presidência da República. De qualquer forma, as políticas econômicas do período 2003-2005 permitiram que o primeiro mandato lulista fosse marcado por inflação anual de 3,1\% e crescimento médio do PIB de aproximadamente $4 \%$, viabilizando sua reeleição em 2006 apesar dos desdobramentos políticos do Mensalão ${ }^{10}$.

\section{Populismo macroeconômico no período 2006-2015}

Antes de caracterizar as políticas econômicas brasileiras entre 2006 e 2015 dentro do arcabouço de Dornbusch e Edwards (1991) se faz necessária uma breve descrição sequencial dos principais eventos econômicos do período.

\subsection{O ponto de inflexão}

Em 27.3.2006 Guido Mantega assumiria o Ministério da Fazenda após o desgaste político de Antonio Palocci com acusações de abuso de poder. Mantega, que ficaria no cargo até o final de 2014, é reconhecido como um quadro do PT ligado à heterodoxia econômica tradicionalmente defendida pelo partido. Após a troca no comado da Fazenda houve clara alteração na postura fiscal do governo, conforme destacado por Giambiagi (2011): afrouxamento dos superávits primários, com utilização sistemática do mecanismo de desconto de investimentos para melhoria dos resultados fiscais (banda de tolerância para a meta fiscal); conflito aberto entre as posições da Fazenda e do Banco Central, que promoveu quatro ciclos de aperto monetário em oito anos; ênfase na mudança da gestão econômica em relação aos governos $\mathrm{FHC}$; expansão expressiva da carteira ativa do BNDES via capitalização por emissão de dívida; uso da contabilidade criativa, como a capitalização da Petrobras em 2010 que gerou artificialmente receita primária de $0,91 \%$ do PIB naquele ano e; aumentos reais maiores do salário mínimo (de 1,2\% no biênio 2003/2004 para 6,1\% nos oito anos posteriores), com impactos significativos nas despesas previdenciárias.

Em 2007 foi lançado pela ministra da Casa Civil, Dilma Rousseff, o Plano de Aceleração do Crescimento (PAC), apresentado como "um programa de ampliação de infraestrutura que combinava expansionismo fiscal e ativismo governamental, para

\footnotetext{
${ }^{9}$ À época, Dilma Rousseff classificou a medida de regulação do dispêndio público de "rudimentar", alegando que "gasto público é vida".

${ }^{10}$ Sobre o escândalo do Mensalão ver Falcão et al. (2013).
} 
'romper barreiras e superar limites', com base em investimentos do próprio governo e das empresas estatais federais" (Werneck 2014, p. 372).

Em que pese o discurso de afastamento das medidas econômicas adotadas anteriormente a 2006, a justificativa para a drástica alteração na gestão fiscal do governo seria a crise do subprime, a partir de 2008. As ações coordenadas entre Banco Central e Ministério da Fazenda, como a implementação de medidas macroprudencias para injeção de liquidez na economia ${ }^{11}$, por exemplo, foram eficientes e permitiram que o país sofresse um pequeno decréscimo no PIB em 2009 (-0,3\%) e apresentasse vigorosa recuperação no ano seguinte, com crescimento de 7,5\%. Contudo, analisandose, por exemplo, os aportes realizados ao BNDES pelo Tesouro Nacional - que alcançaram a cifra de $\mathrm{R} \$ 524$ bilhões entre 2006 e 2013 - a crise externa se apresenta como um álibi para a consolidação de um novo regime fiscal. Conforme destacado em Werneck (2014):

“No Brasil, esse desdobramento da crise econômica mundial foi até festejado pelo governo, pois lhe abriu a oportunidade, que em condições normais jamais teria, de legitimar mudanças importantes no regime fiscal e nas relações entre o Estado e a economia. [...] De início, o afrouxamento fiscal que, em boa parte, era simples decorrência de decisões tomadas antes da crise, foi racionalizado como política contracíclica." (Werneck 2014, p.375, grifo meu)

Pessôa (2018) também destaca que a partir de 2006 instalou-se uma agenda intervencionista no Ministério da Fazenda. Segundo o autor desonerações discricionárias, alterações regulatórias, hipertrofia dos bancos públicos, empréstimos subsidiados e desajuste fiscal passaram a compor a rotina da formulação da política econômica, a qual ficou alinhada com a retórica do "gasto público é vida". O Quadro 1 exemplifica a alteração da conduta fiscal do governo, especificamente sob o ângulo da política de crédito direcionado pelo BNDES ${ }^{12}$ no pós-crise do subprime (2009).

Todavia, a alocação dos recursos realizada pelo BNDES havia sido alterada a partir 2006 - com a edição da Medida Provisória (MP) 315 que injetou R \$5 bilhões do Tesouro no capital da instituição - visando beneficiar setores específicos, como o petrolífero, a indústria naval e a geração e distribuição de energia, cujas empresas atuantes, como regra, possuem grande porte e acesso ao mercado de capitais. Ao final de 2015 a carteira ativa do banco somava R\$930 bilhões (em torno de 15,7\% do PIB), com crescimento $360 \%$ em relação à dezembro de 2007, quando o valor era de

\footnotetext{
${ }^{11}$ O estudo de Carvalho e Castro (2016) apresenta análise sobre as medidas macroprudenciais adotadas durante a crise.

${ }^{12}$ Para mais detalhes sobre os custos do crédito subsidiado ver Mendes (2014).
} 
aproximadamente $\mathrm{R} \$ 203$ bilhões (em torno de 7,5\% do PIB) ${ }^{13}$. Mesmo com transferências maciças de renda a setores escolhidos, a formação bruta de capital fixo declinou 2,1 pontos percentuais entre 2011 e 2014.

De acordo com Rosa (2015, p. 11) “o sistema de alocação de recursos do BNDES não respeita nenhum princípio de mercado, sendo fruto da política industrial escolhida pelas autoridades públicas", e o banco "aumenta o crédito disponível na economia, porém o BNDES financia seu subsídio via tributos sobre a renda do trabalho, o que distorce as decisões de consumo e trabalho das famílias". Pode-se contrastar o enorme fluxo de recursos a setores específicos, por exemplo, com os custos dos programas de transferência de renda do Governo Federal - como o Bolsa Família - cujos desembolsos entre 2003 e 2015 totalizaram aproximadamente R\$187 bilhões segundo o Ministério do Desenvolvimento Social e Agrário (MDS).

\begin{tabular}{|l|l|}
\hline jan/09 & MP 453 permite aporte de R $\$ 100$ bilhões do Tesouro ao BNDES \\
abr/09 & $\begin{array}{l}\text { Redução da meta primária de } 2009 \text { de } 3,3 \% \text { para 2,3\% do PIB, com } \\
\text { permissão de abatimento adicional de } \mathrm{R} \$ 17,9 \text { bilhões }\end{array}$ \\
\hline dez/09 & MP 472 autoriza o Tesouro injetar mais $\mathrm{R} \$ 180$ bilhões no BNDES \\
\hline set/10 & MP 505 autoriza o Tesouro injetar mais $\mathrm{R} \$ 30$ bilhões no BNDES \\
\hline dez/10 & Superávit primário efetivo de $1,8 \%$ do PIB, ante meta de 3,3\% \\
\hline mar/11 & MP 526 autoriza o Tesouro injetar mais $\mathrm{R} \$ 55$ bilhões no BNDES \\
\hline ago/11 & $\begin{array}{l}\text { Governo envia proposta orçamentária ao Congresso com previsão de } \\
\text { aumento de } 15,4 \% \text { nos gastos em meio à crise na periferia europeia (PIIGS) }\end{array}$ \\
\hline
\end{tabular}

Quadro 1 - Postura fiscal brasileira pós-crise subprime

Fonte: O Autor e Senado Federal (2017).

\subsection{A Nova Matriz Econômica}

Existe certo grau de dificuldade em delinear academicamente a política econômica do primeiro governo Dilma Rousseff (2011-2014), uma vez que não há documentos formais unificando as principais estratégias macroeconômicas do período. Todavia, alguns registros na imprensa especializada oriundos de funcionários do alto escalão federal durante o período permitem inferir quais eram os objetivos centrais do governo.

Em 19.12.2012 o Jornal Valor Econômico publicou o texto intitulado “O primeiro ano da nova matriz econômica ${ }^{14 "}$, assinado pelo mais longevo Ministro da Fazenda da

\footnotetext{
13 Os dados sobre a carteira do BNDES estão disponíveis nos diversos Relatórios de Atividade, em https://web.bndes.gov.br/bib/jspui/handle/1408/706.

${ }^{14}$ Disponível em http://www.valor.com.br/brasil/2945092/o-primeiro-ano-da-nova-matriz-economica.
} 
história do país. Dada a relevância ao presente estudo é reproduzida a seguir grande parte do texto original:

"O Brasil vive um momento de mudança estrutural em sua economia. Depois da estabilização de preços promovida pelo Plano Real, da revolução inclusiva e distributiva a partir de 2003 e da mudança de patamar de crescimento econômico a partir de 2006, o país agora passa por nova mudança fundamental: a colocação das taxas de juros em níveis normais para uma economia sólida e com baixo risco. [...] O governo Dilma Rousseff elegeu como um dos seus principais desafios dar um salto de competitividade na economia brasileira, sem abrir mão de se manter na rota da inclusão social e da redução da desigualdade trilhada nos anos precedentes. Nesse sentido, colocavase como absolutamente estratégico remover, ou pelo menos minimizar, a distorção que havia nos dois principais preços do país: juros e câmbio. [...] $\mathrm{Na}$ redução de tributos foi dada ênfase à desoneração da folha de pagamentos, que neste ano beneficiou quinze setores e, a partir de 2013, alcançará mais de quarenta. Essa medida tem a grande virtude de reduzir o custo de mão de obra no Brasil sem reduzir os direitos dos trabalhadores, que costumam aparecer como os primeiros prejudicados em tempos de crise econômica (como está ocorrendo, por exemplo, na Europa). [...] Anunciamos também uma medida crucial para baratear os custos produtivos no Brasil: a redução do preço da energia. A despeito do equívoco de avaliação e da falta de cooperação de algumas empresas dos Estados de São Paulo, Minas Gerais, Paraná e Santa Catarina, conseguimos garantir que, a partir de fevereiro de 2013, a conta de luz cairá em torno de 20\%, na média. Certamente essa é uma medida de alto impacto na produção nacional e vai alavancar nossa competitividade. Também vale destacar a redução do custo financeiro para o investimento. Além da já mencionada mudança estrutural na taxa Selic, reduzimos a taxa de juros do Programa de Sustentação do Investimento (PSI) para 2,5\% ao ano no último trimestre de 2012. E recentemente anunciamos a renovação do programa para 2013, com taxa média em torno de 3,5\% ao ano e $\mathrm{R} \$ 100$ bilhões disponíveis para as empresas tomarem emprestados no sistema financeiro. [...] Os outros $\mathrm{R} \$ 85$ bilhões serão emprestados dentro do sistema BNDES, que tem sido o grande impulsionador dos investimentos. Nosso objetivo é que, no ano que vem, os investimentos no Brasil cresçam o dobro do PIB, como ocorreu em quase todos os anos desde 2006. [...] A despeito do crescimento 
abaixo do previsto por nós e por todos os analistas, 2012 foi um ano extremamente importante para o futuro da economia brasileira. A recuperação de taxas mais vigorosas de crescimento do PIB já está em curso e isso ficará claro em 2013. Mas o mais importante é que estão fixadas as bases para que o Brasil tenha taxas elevadas de crescimento por muitos anos, melhorando o emprego, a renda e diminuindo as desigualdades que subsistem em nosso país". (Mantega 2012).

Dois dias antes, no mesmo veículo de imprensa, o então Secretário de Política Econômica havia concedido entrevista explicando o tripé de sustentação da nova matriz: taxa de juros baixa; taxa de câmbio competitiva, e consolidação fiscal "amigável" ao investimento.

Infere-se das transcrições acima que a Nova Matriz Econômica tratou da continuidade de projeto deliberado pelo primeiro escalão do poder executivo federal, iniciado ainda ao final do primeiro governo Lula sem quaisquer discussões no Congresso Nacional, de maneira similar ao orçamento monetário e à conta movimento, que usurpavam prerrogativas da Câmara dos Deputados e do Senado Federal até meados da década de 1980.

No Brasil pós-boom chinês, que alterou favoravelmente nossos termos de troca por quase uma década, a manutenção do modelo baseado em estímulos ao crédito e à demanda - herdado do segundo Governo Lula - foi viabilizada no Governo Dilma pela importação de deflação do mundo desenvolvido ainda em recuperação lenta da crise do subprime. Assim, iniciou-se a redução forçada dos juros, o aumento de subsídios setoriais, a expansão do crédito público e, já em seus momentos finais, a utilização indiscriminada de controle de preços e do câmbio, políticas que minariam a confiança dos agentes econômicos culminando na maior recessão do Brasil Republicano. A Nova Matriz representa o auge do populismo macroeconômico, conforme destacado no próximo item.

\subsection{O Populismo Macroeconômico}

De acordo com Dornbusch e Edwards (1991), o populismo macroeconômico é definido, em tradução livre, como a "gestão econômica que fomenta o crescimento e a distribuição de renda desconsiderando os riscos inflacionários, o financiamento da dívida pública, as restrições externas e a reação dos agentes econômicos ao intervencionismo excessivo." Segundo os autores - que comparam em seu estudo a macroeconomia de Allende no Chile e Garcia no Peru, nos anos 1970 - as principais características do paradigma populista seriam:

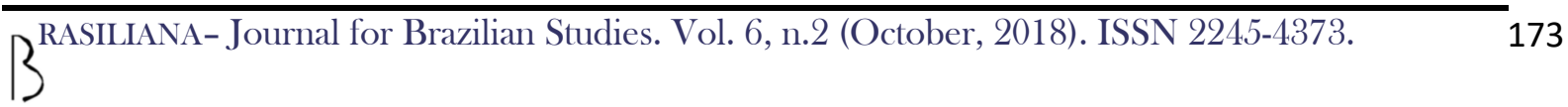


a) Condições iniciais - o poder incumbente e grande parte da população sentem-se insatisfeitos com o desempenho da economia resultando num sentimento generalizado de que "as coisas podem ser melhores" (Dornbusch e Edwards 1991, p. 9);

b) Desconsideração de restrições - as autoridades explicitamente rejeitam quaisquer restrições macroeconômicas. Capacidade ociosa e a existência de reservas internacionais permitem políticas expansionistas sem riscos ao balanço de pagamentos ou à inflação devido aos custos decrescentes de longo prazo que contêm as pressões produtivas, além da possibilidade de redução de lucros via controle de preços;

c) Políticas econômicas - dados os elementos iniciais descritos anteriormente, os programas populistas enfatizam três elementos: crescimento, redistribuição de renda e reestruturação da economia.

Com a implementação das políticas populistas, o processo macroeconômico se desenvolve em quatro fases, observadas as idiossincrasias para cada país e época. Inicialmente os propositores das políticas sentem-se reverenciados em seus diagnósticos e prescrições, pois se observa aumento no crescimento do PIB e nos salários reais com concomitante queda no desemprego. A inflação ainda se mantém relativamente estável e desequilíbrios entre oferta e demanda são compensados com importações, as quais podem ser financiadas com reservas ou calotes.

Na segunda fase começam os gargalos devido ao excesso de demanda interna ou por falta de dólares. Realinhamento de preços, desvalorização cambial ou aumento do protecionismo se tornam necessários. O governo tenta, em vão, estabilizar a economia com aumento do salário real e crescimento da despesa. A inflação aumenta, os salários tendem a acompanhar o movimento dos preços e o déficit público aumenta de forma significativa.

No terceiro estágio há racionamentos, aceleração da inflação, fuga de capital devido ao baixo nível de reservas e se inicia o uso de outras moedas como referência de valor. Observa-se grande aumento no déficit público uma vez que há redução na arrecadação e aumento nos custos dos subsídios. Dessa forma, resta ao governo cortar gastos, induzir a desvalorização real da moeda e reduzir os salários reais, deixando claro que as medidas populistas fracassaram. Tem início a instabilidade política.

Por fim, na quarta fase, começa o programa ortodoxo de estabilização sob um novo governo, com a principal característica sendo a queda significativa e persistente do salário real derivada da queda nos investimentos. Segundo Dornbusch e Edwards (1991, p. 12) "o capital consegue fugir de políticas ruins, o mesmo não ocorre com o trabalho."

O paradigma populista brasileiro está cristalizado nos registros sobre o período 2006-2015 citados neste trabalho, encontrando-se os elementos revelados por 
Dornbusch e Edwards (1991), especialmente na retórica: (i) do afastamento das políticas recessivas de governos anteriores (Giambiagi 2011) e da mudança de patamar de crescimento econômico a partir de 2006 (Mantega 2012); (ii) da completa desconsideração pelas restrições impostas a uma economia de mercado com a estratégia de "remover, ou pelo menos minimizar, a distorção que havia nos dois principais preços do país: juros e câmbio" (Mantega 2012); e (iii) da linha mestra do crescimento com redistribuição, presente na sentença em que se garantem "as bases para que o Brasil tenha taxas elevadas de crescimento por muitos anos, melhorando o emprego, a renda e diminuindo as desigualdades que subsistem em nosso país" (Mantega 2012).

Sobre o desdobramento das fases do populismo macroeconômico no Brasil (2006-2015), destacam-se os seguintes indicadores:

a) Primeira fase (2006-2013) - o discurso da reverência é bastante óbvio ao longo de todo o artigo do primeiro ano da nova matriz (Mantega 2012), com destaques a uma nova economia "sólida e com baixo risco" e a manutenção dos "direitos dos trabalhadores em oposição às políticas de nações europeias", por exemplo. O boom nos preços das commodities viabilizou a manutenção do equilíbrio no Balanço de Pagamentos, não sendo necessário o uso das reservas ou calotes para a liquidação das importações. Todavia, se utilizarmos os preços de 2005 das principais commodities exportadas pelo Brasil (soja e minério de ferro), o superávit no saldo comercial de R \$21 bilhões em 2010 passaria para déficit de R \$20 bilhões, aproximadamente;

b) Segunda fase (2014) - O elevado consumo pela China das commodities produzidas no Brasil no início do século XXI impediu gargalos por falta de dólares. No entanto, a Tabela 3 mostra a evolução de algumas variáveis macroeconômicas no período analisado e, claramente, observam-se os fenômenos de realinhamento de preços (IPCA) e aumento do déficit público (NFSP) a partir de 2014, além da desvalorização cambial;

c) Terceira fase (2015) - Novamente, a Tabela 3 demonstra o grande aumento no déficit público devido à queda na arrecadação (acompanhando o PIB, que decresceu 7\% no biênio 2015-2016) e a tentativa, em vão, de manutenção dos salários reais via câmbio (operações de swap do Banco Central ${ }^{15}$ ), deixando claro que as medidas populistas fracassaram. Tem início a instabilidade política, com aumento do desemprego e diversos setores da sociedade incluindo o próprio partido da presidenta - criticando as medidas adotadas para a contenção de gastos, sob a gestão do Ministro Joaquim Levy na Fazenda. Em dezembro o pedido de impeachment é aprovado na Câmara dos Deputados;

\footnotetext{
${ }^{15}$ Em 2014 o custo de evitar uma grande desvalorização do câmbio via swaps foi de R $\$ 17,3$ bilhões e, em 2015, de $\mathrm{R} \$ 89,7$ bilhões.
}

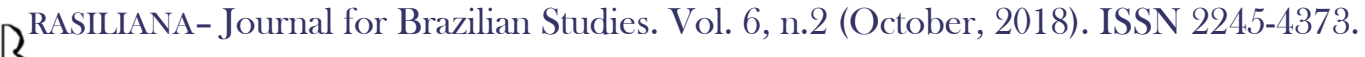


d) Quarta fase (2016) - começa o programa ortodoxo de estabilização sob um novo governo, no caso, sob a presidência de Michel Temer, vice da chapa eleita em 2014. As principais medidas para a estabilização da economia consistem na Proposta de Emenda Constitucional n 55 (a PEC do teto dos gastos públicos), aprovada pelo Senado em dez/2016 e na reforma da previdência, ainda sem aprovação no Congresso no início das atividades parlamentares de 2018 .

Ressalta-se, mais uma vez, que apesar de existirem praticamente todos os elementos do populismo macroeconômico (Dornbusch e Edwards 1991) não há, a princípio, previsão de crise cambial no Brasil atualmente. Além da disparada nos preços das commodities exportadas pelo país no início do Século XXI, fato que permitiu o grande acúmulo de reservas em moedas conversíveis, a manutenção da taxa de juros básica dos EUA em níveis muito baixos desde as primeiras reações à crise do subprime tem impedido a fuga de capitais. Finalmente, cabe mencionar que no início de 2016 o Governo Dilma cogitava usar as reservas internacionais, de maneira inédita, para abater parte da dívida pública federal.

Tabela 3 - Indicadores Macroeconômicos selecionados (2006-2016)

\begin{tabular}{llllllll}
\hline & $\begin{array}{l}\text { PIB per capta } \\
\text { (US\$ PPC) }\end{array}$ & $\begin{array}{l}\text { Inflação } \\
\text { IPCA (\%) }\end{array}$ & $\begin{array}{l}\text { Taxa } \\
\text { Desemprego }\end{array}$ & $\begin{array}{l}\text { (\%) } \\
\text { (\% PIB) } \\
\text { (\%) }\end{array}$ & $\begin{array}{l}\text { Cambio } \\
\text { real }^{* *}\end{array}$ & $\begin{array}{l}\text { Salário } \\
\text { real } \\
\text { jan) }\end{array}$ & (R\$, \\
\hline $\mathbf{2 0 0 6}$ & 11.730 & 3,14 & 9,20 & 3,09 & 96,10 & 1.856 \\
$\mathbf{2 0 0 7}$ & 12.630 & 4,45 & 8,90 & 2,19 & 79,55 & 1.941 \\
$\mathbf{2 0 0 8}$ & 13.370 & 5,90 & 7,80 & 0,80 & 100,79 & 1.982 \\
$\mathbf{2 0 0 9}$ & 13.300 & 4,31 & 9,10 & 3,22 & 72,56 & 2.076 \\
$\mathbf{2 0 1 0}$ & 14.340 & 5,90 & 6,70 & 1,18 & 67,27 & 2.106 \\
$\mathbf{2 0 1 1}$ & 15.060 & 6,50 & 7,30 & 2,00 & 70,55 & 2.190 \\
$\mathbf{2 0 1 2}$ & 15.470 & 5,83 & 6,70 & 1,27 & 76,71 & 2.278 \\
$\mathbf{2 0 1 3}$ & 16.000 & 5,91 & 7,10 & 2,07 & 83,00 & 2.340 \\
$\mathbf{2 0 1 4}$ & 16.150 & 6,41 & 7,50 & 4,70 & 88,49 & 2.449 \\
$\mathbf{2 0 1 5}$ & 15.690 & 10,67 & 8,50 & 8,56 & 118,15 & 2.439 \\
$\mathbf{2 0 1 6}$ & 14.810 & 6,29 & 11,5 & 6,69 & 98,08 & 2.251 \\
\hline
\end{tabular}

Fontes: FMI e Banco Central do Brasil (2017).

Notas: *Sem desvalorização cambial - Resultado nominal - Governo Federal e BC. ** Índice da taxa de câmbio real (IPCA) - Jun/1994=100 - Dólar americano 


\subsection{Falhas institucionais}

De acordo com Acemoglu (2009), diferentes instituições geram alocações econômicas distintas e a solução para o conflito distributivo inerente depende de como o poder político é distribuído na sociedade. Ou seja, diferentes arranjos políticos induzem diferentes instituições econômicas que, por sua vez, são responsáveis por diferentes resultados econômicos.

No Brasil, as preferências reveladas pelas instituições econômicas demonstram que as instituições políticas nunca permitiram a resolução do conflito distributivo através das escolhas da sociedade, ou seja, via ampla discussão do orçamento público e suas restrições no Congresso Nacional.

Em 1960, último ano de governo, Juscelino Kubitschek começou a traçar uma estratégia para seu partido - o PSD - perder as eleições. Segundo Schwarcz e Starling (2015, p. 429) "a situação financeira do país era grave, o governo não tinha controle sobre os gastos, e seu sucessor precisaria adotar um programa rigoroso de austeridade econômica." Além disso, a estratégia envolvia transferir todo o ônus das políticas de combate à inflação para o partido da oposição permitindo que nas eleições de $1965 \mathrm{JK}$ retornasse com um novo programa de crescimento. Não houve tempo, e o total descontrole das contas públicas foi parcialmente resolvido por um regime repressivo que inicialmente reduziu os salários reais e, ao seu final em 1985, havia sido responsável pelo avanço da industrialização, mas também pelo aumento vertiginoso na concentração de renda no país.

Apesar dos avanços, as instituições políticas brasileiras ainda geram alocações econômicas muito ineficientes, fato observado no padrão stop-and-go de crescimento da renda e na consequente instabilidade social. Os presidentes João Goulart e Fernando Collor de Mello não resistiram às crises inflacionárias dos anos 1960 e 1990, respectivamente; Dilma Rousseff sucumbiu à recessão iniciada em $2014^{16}$.

\section{Conclusões}

Até a obtenção da plena governança da moeda pelo Banco Central a partir do Plano Real (1994) e, posteriormente, a consolidação do novo arranjo institucional com o Regime de Metas para Inflação (1999), o imposto inflacionário configurou-se no caminho de menor resistência para o equacionamento da contas públicas no Brasil.

\footnotetext{
16 Segundo o CODACE - Comitê de Datação de Ciclos Econômicos do Instituto Brasileiro de Economia (IBRE/FGV) - o Brasil entrou em recessão no segundo trimestre de 2014.
} 
Todavia, após um breve interlúdio, a disputa por recursos públicos à revelia do Congresso Nacional, que anteriormente ocorria na arena monetária, movimentou-se para a esfera fiscal através da concessão de subsídios e da emissão de dívida. A partir de 2006 observa-se a implementação de políticas públicas desconsiderando as restrições orçamentárias que lastreiam o pleno funcionamento de uma economia de mercado, em linha com o arcabouço teórico definido como populismo macroeconômico por Dornbusch e Edwards (1991).

Os autores ressaltam que, embora os resultados das experiências populistas sejam previsíveis e nocivos à maioria da população, como regra há boa intenção nas ações dos responsáveis pela idealização dos programas de desenvolvimento. No Brasil, a retórica do "gasto público é vida" remonta ao projeto de desenvolvimento baseado na industrialização por substituição de importações, no qual a forte presença do Estado na economia era considerada essencial para o crescimento - e o resultado inflacionário, incontestável. Franco (1998, p. 39) alertava, ainda num contexto de incertezas sobre a resiliência do Plano Real, que não se deveria subestimar o poder de tal retórica porque ela "se cristaliza em mitos, encastelada no inconsciente coletivo, gerando consequências ao nível das doutrinas e da organização política" e, dessa forma, "a todo momento estamos enfrentando tensões ao desafiar o que parece ser uma sabedoria solidamente estabelecida".

Conclui-se essencialmente que a guinada fiscal iniciada em 2006 comprometeu as finanças públicas através da concessão de abrangentes desonerações tributárias e de crédito subsidiado, gerando distorções nos mecanismos de formação de preços e impactando negativamente tanto o perfil da dívida mobiliária federal quanto as expectativas dos agentes. O ápice do processo encontra-se na implementação da Nova Matriz Econômica, a partir de 2012, e o resultado final, no período recessivo 2014-2016.

Um avanço institucional visando tornar mais eficiente a proxy fiscal aqui analisada (crédito subsidiado via emissão de dívida) acontecerá com a redefinição da Taxa de Juros de Longo Prazo (TJLP) - o custo do capital - como uma função dos juros dos títulos emitidos pelo Tesouro atrelados à inflação (NTN-B) - o custo de captação real do governo - reduzindo o peso da equalização de juros do BNDES.

Mesmo com o Novo Regime Fiscal buscado através da PEC/55 não se vislumbram alterações estruturais de maior vulto, conforme esclarecido pelo próprio Ministério da Fazenda na Exposição de Motivos da proposta: "Ele [o teto para os gastos públicos] não é um instrumento que resolverá todos os problemas das finanças públicas federais. As regras aqui propostas só funcionarão se forem bem utilizadas por um governo imbuído de responsabilidade fiscal. A experiência do passado recente mostra que não há regra de conduta fiscal que seja blindada contra intenções 
distorcidas, mas o desenho institucional desta PEC dificultará no período de sua vigência o aumento da despesa primária do governo central."17

Déficits públicos geradores de inflação elevada ou crises fiscais são o resultado econômico de instituições políticas que dificultam uma tributação eficiente da sociedade, permitindo à nação viver, de maneira efêmera, acima de seus meios. $\mathrm{O}$ padrão de crescimento stop-and-go resultante de uma estrutura de gastos públicos que desconsidera as restrições de receita impõe sacrifícios elevados aos mais fracos socialmente ou às gerações futuras, como comprova a trajetória brasileira ao longo das últimas sete décadas. Apesar dos avanços lastreados na Constituição Federal e expressos, principalmente, na estabilização monetária, no Regime de Metas para Inflação e na legislação relativa à responsabilidade fiscal, o arranjo institucional vigente no Brasil aparenta ser insuficiente, embora necessário, para garantir a estabilidade macroeconômica. Ainda falta à nação a cultura de responsabilidade fiscal.

\section{Referências}

Acemoglu, D. 2011. Introduction to Modern Economic Growth. Princeton University Press, 2009.

Banco Central do Brasil. 2011. Dez anos de metas para a inflação - 1999-2009. Brasília: Banco Central do Brasil.

Banco Central do Brasil. 2013. Ata da 172ª reunião do Comitê de Política Monetária Copom.

Banco Central do Brasil. 2017. Sistema Gerenciador de Séries Temporais. Acesso em 22 de janeiro de 2017. https://www3.bcb.gov.br/sgspub/ localizarseries/

Banco Nacional de Desenvolvimento Econômico e Social (BNDES). 2017. Relatório de Atividade - 2007-2014. Acesso em 10 de janeiro de 2017. https://web.bndes.gov.br/bib/jspui/handle/1408/706

Calomiris, C.W. and Haber, S.H. 2014. Fragile by Design: The Political Origins of Banking Crisis and Scarce Credit. Princeton: Princeton University Press.

${ }^{17}$ EMI no 00083/2016 MF MPDG, item n ${ }^{\circ} 18$.

RASILIANA-Journal for Brazilian Studies. Vol. 6, n.2 (October, 2018). ISSN 2245-4373. 179 
Carvalho, F.A. and Castro, M.R. 2016. Macroprudential Policy Transmission and Interaction with Fiscal and Monetary Policy in an Emerging Economy: a DSGE Model for Brazil. Working Paper 453. Brasília: Banco Central do Brasil.

Dornbusch, R. and Edwards, S. 1991. The Macroeconomics of Populism in Latin America. Chicago: The University of Chicago Press.

Falcão, J. (Org). 2013. Mensalão: Diário de um julgamento. Rio de Janeiro: Elsevier.

Fundo Monetário Internacional (FMI). 2017. IMF Data. Acesso em 16 de fevereiro de 2018. https://www.imf.org/en/Data.

Franco, G.H.B. 1998. A inserção externa e o desenvolvimento. Revista de Economia Política 18(3):71.

Franco, G.H.B. 2015. 50 Anos do Banco Central. Acesso em 10 de janeiro de 2017. http://www.gustavofranco.com.br/.

Franco, G.H.B. 2017. A moeda e a lei: uma história monetária brasileira (1933-2013). Rio de Janeiro: Zahar.

Giambiagi, F. e Pinheiro, A.C. 2012. Além da euforia: riscos e lacunas do modelo brasileiro de desenvolvimento. Rio de Janeiro: Elsevier.

Giambiagi, F. 2011. Rompendo com a ruptura: o Governo Lula (2003-2010). In: Giambiagi, F.; Villela, A.; Barros de Castro, L. e Hermann, J. Economia Brasileira Contemporânea [1945-2010]. Rio de Janeiro: Elsevier.

Gremaud, A.P.; Vasconcellos, M.A. e Júnior, R.T. 2002. Economia Brasileira Contemporânea. $4^{\mathrm{a}}$ ed. São Paulo: Atlas.

Jaloretto, C. 2006. Senhoriagem e Financiamento do Setor Público no Brasil. Brasília: Tesouro Nacional. Coletânea de Monografias do XI Prêmio Tesouro Nacional.

Lima, E. 2002. Disciplina fiscal no Brasil: atuais instituições garantem equilíbrios permanentes?. Brasília: Tesouro Nacional. Coletânea de Monografias do VII Prêmio Tesouro Nacional 
Mantega, G. 2012. O primeiro ano da nova matriz econômica. Acesso em 8 de dezembro de 2016. http://www.valor.com.br/brasil/2945092/o-primeiro-ano-da-nova-matrizeconomica

Mendes, M. 2014. Por que o Brasil cresce pouco?. Rio de Janeiro: Elsevier Editora.

Pastore, A.C. 2015. Inflação e Crises: o papel da moeda. Rio de Janeiro: Elsevier Editora.

Pessôa, S. 2018. Depressão brasileira: causas passadas ou presentes? In: Conjuntura Econômica, v.72, $\mathrm{n}^{\circ} 05$. Rio de Janeiro: FGV/IBRE.

Prado Junior, C. 2011. Formação do Brasil Contemporâneo, 1942. São Paulo: Companhia das Letras.

Rosa, R.M. 2015. Implicações macroeconômicas do BNDES. São Paulo: FGV/EESP.

Schwarcz, L.M. and Starling, H.M. 2015. Brasil: uma biografia. São Paulo: Companhia das Letras.

Senado Federal. 2017. Atividade Legislativa - 2009-2011. Acesso em 7 de dezembro de 2016. http://www25.senado.leg.br/web/atividade/materias.

Senna, J.J. 2015. Prefácio, 2014. In: Pastore, Affonso Celso. Inflação e Crises: o papel da moeda. Rio de Janeiro: Elsevier.

Schumpeter, J.A. 1964. História da Análise Econômica. Rio de Janeiro: Fundo de Cultura.

Simonsen, M.H. e Cysne, R.P. 2009. Macroeconomia. 4ª ed. São Paulo: Editora Atlas.

Werneck, R.L.F. 2014. Alternância política, redistribuição e crescimento, 2003-2010. In: Abreu, Marcelo de Paiva. A ordem do Progresso: dois séculos de política econômica no Brasil. Rio de Janeiro: Elsevier. 